\title{
The Mediation Effect of Overall Brand Equity between Brand Superiority and Media Consumption Behaviours of Sport Team Consumers During COVID-19
}

\author{
Kadir Yağiz \\ Republic of Turkey Ministry of National Education, Ankara, Turkey
}

\begin{abstract}
Background. During the COVID-19 pandemic, it is paramount to investigate how to influence professional sport team consumers' behaviours towards media consumption, which is an indirect consumption of sports products with importance raised by the lockdown. The effect of brand superiority, one of the essential consumer judgments about the brands, on some behavioural intentions of sport team consumers was examined before; however, the role of brand superiority and overall brand equity on media consumption behaviours in pandemic conditions lacked empirical investigation. Therefore, this study aims to examine the relationship between brand superiority, overall brand equity and media consumption behaviours among professional sports teams' consumers during the COVID-19 pandemic.

Methods. The participants of this quantitative study were 232 volunteer football (soccer) consumers who support a team in the Turkish Super Football League. The data was collected in 3 weeks using the online convenience sampling method. Confirmatory factor analysis (CFA) and structural equation modelling (SEM) were used in data analyses, and direct and indirect paths tested by the bootstrapping method.

Results. The results of the study showed that brand superiority did not have a direct effect on media consumption behaviours of sport team consumers. Besides, overall brand equity had a direct effect on media consumption behaviours and mediated the relationship between brand superiority and media consumption behaviours.

Conclusions. The evidence in this study indicates sport managers that the cognitive judgement of sport consumers, generally related to the more functional aspect of a sports product alone not an efficient way to directly influence sport team consumers toward media consumption behaviours even in COVID-19 pandemic. Brand equity, however, was found to be an effective tool to address for directing sport team consumers' behaviours toward media consumption in the extraordinary circumstance currently existing.
\end{abstract}

Keywords: branding, sports industry, spectator sports, professional sports teams, sports consumers.

\section{INTRODUCTION}

A s the COVID-19 outbreak has been dramatically changing our daily habits with the restrictions to prevent the spread, it has also forced sport governing bodies to impose critical decisions globally for both the participant and the spectator sport at all levels (e.g., amateur and professionals) to protect all involved parties (e.g., athletes, spectators). Immediately after the
World Health Organization declared COVID-19 as a pandemic on March 11, 2020 (T.C. Sağlik Bakanlığ 1$)_{2}$ many major sporting events began to be cancelled or postponed in an unprecedented manner as a first response. During the pandemic, the whole professional sports industry, including football, was negatively affected from a financial perspective. For instance, from the middle of March to June 2020, no 
matches were played in European football leagues, and most leagues restarted in June 2020 behind closed doors without spectators in the stadium (Drewes, Daumann, \& Follert, 2021). The Deloitte Sport Business Group (Deloitte, 2020a) forecast that the 2019/20 years' revenues of Premier League clubs would decrease by approximately $€ 1$.1bn due to the disruption in the 2019/20 season, and about $50 \%$ of this loss would be mainly due to the loss of matchday revenues and rebates on broadcast and commercial contracts.

In the 2018/19 season, the matchday revenues of the "big five" European league clubs constituted between $11 \%$ to $16 \%$ of total revenues, whereas broadcasting revenues constituted between $44 \%$ to $59 \%$ (Deloitte, 2020b). In modern football marketing and economy, although the matchday revenues are relatively less vital for big clubs and leagues compared with broadcasting and sponsorship revenues, from an economic perspective, all have been losing these significant revenue sources during the pandemic. According to the Deloitte Sport Business Group (Deloitte, 2020a), the course is likely to be made worse by the COVID-19 pandemic for smaller clubs as they depended on more heavily matchday revenues. Academic studies also point out this fact. For example, according to the study of Horky (2021) in Germany's Bundesliga, where the average spectators per game are high $(42,738)$, the share of revenue generated by spectators $(12.9 \%)$ in the total income is much less than the share of media revenue $(66.1 \%)$ covering TV contacts and other media-related revenue. Conversely, in hockey and handball leagues, where the average spectators per game are fewer $(6,215$ and 4,808 respectively), the share of revenue generated by spectators in the total income is $32.2 \%$ and $26.0 \%$, while the share of media revenue is $14.4 \%$ and $3.0 \%$, respectively. Statistics show that different sources of revenue have a varying share in the total income of the leagues, but each sports league is somehow dependent on the spectators or audiences for different reasons. For example, leagues such as Bundesliga and the Premier League and their clubs are less dependent on matchday revenue than smaller ones, due to their ability to compensate the losses in matchday revenues with other commercial contracts during this lockdown. However, to fulfil their obligations towards broadcasters and sponsorships and maintain their revenues, they still depend on the continuation of matches in leagues even with "ghost games" (the games without spectators) and a maintain large audience base.
According to the Deloitte Sport Business Group (Deloitte, 2020c), both football clubs and their broadcasters and commercial partners will face economic challenges in the 2020/21 season in issues such as the uncertainty of timing and nature of the fans' returning to the stadium, as well as changes in the attendance and interaction of consumers with the sport during the lockdown. Drewes et al. (2021) also noted that even before COVID-19, some industry representatives had anticipated that professional matches played without the typical stadium atmosphere (i.e., applauding, booing, singing) created by fans could have an impact on the marketability of television rights, and interest in the transmission of matches played without spectators, and the desire to pay TV could decline, and in turn affect the value of TV rights. Sport organizers have already been adapting innovative ways to maintain sport consumers for some time. For example, they use virtual reality technology, which generates images, sounds and sensations that affords consumers a better consumption experience (The Business Research Company, 2020). However, it looks like sports organizers will focus on engaging consumers by developing contingency plans for "ghost games" and seek opportunities for virtual technologies to grow in the coming days (Marbella International University Centre, 2020). Therefore, the "new normal" conditions caused by the pandemic can accelerate and cause lasting changes in the understanding of sports marketing and broadcasting. Although COVID-19 posed challenges for both sports teams and broadcasters, they initially managed to demonstrate exemplary entrepreneurial flexibility by continuing and broadcasting ghost games as complying with the political restrictions (Drewes et al., 2021). As the commercial relationships between sports teams and broadcasters, other media channels and sponsors continue under existing agreements, it remains unclear where these relations will evolve in the longer term. Therefore, during the lockdown period, it is predicted that the need for sports teams to prove their values as a brand to their commercial partners will be greater than ever, as it is thought that sponsors and broadcasters will be more sensitive to brand alignment and common purpose in the teams that wanted to be associated (Deloitte, 2020c). The fact that the matches were played without spectators during the pandemic showed once again the importance of the consumption of professional sports through the media, which will also be valid 
in similar crisis that may occur in the future. It is also likely that these extraordinary circumstances may put pressure on clubs to better understand and build relationships with their supporters in an increasingly competitive sports market (Deloitte, 2020c) and further strengthen and position their brands for the media and other commercial partners which want to reach out these masses that will be valuable for them. Ultimately, sports teams with a large consumer base are more attractive for all media channels and other commercial partners (Gladden, Irwin, \& Sutton, 2001). In addition, for sports teams, the acquiring and sustainability of direct (e.g., matchday revenue) and indirect (e.g., media rights) income sources depend, in some way, on a large fan base. Hence, during this challenging time, the managers of professional sports teams need to understand how to influence sport consumers' behaviours toward the consumption of their team brand via media through the affectively managing of their sources. One of the most effective assets of professional sports teams to use in manipulating their consumers' attitude and behaviours is the brand they have. Therefore, this study aims to examine the relationship between brand superiority, overall brand equity and media consumption behaviours in professional sports teams' consumers during the COVID-19 pandemic. Specifically, this research investigates whether brand superiority and overall brand equity have an impact on media consumption behaviours and whether overall brand equity mediates the relationship between brand superiority and media consumption behaviours in spectator sports during the COVID-19 pandemic.

According to Zeithaml (1988), the superiority of a product is judged through perceived quality by consumers and achieving a brand superiority over competitors seen as one of the primary goals of effective branding (Gordon \& James, 2017). Brand superiority also defined as consumers' judgement that a brand is unique, different and better than others in terms of providing advantages and seen as essential for building an intense and active relationship with customers (Keller, 2001). In industrial or even in some services brand, brand superiority is more linked with the subjective evaluation of a brand's functional aspects. In spectator sports, however, consumption is generally experiential rather than functional (Bauer, Sauer, \& Exler, 2005), and this may cause the function of brand superiority questionable in explaining sport team consumers' attitude and behaviours related to their teams. A previous study (Gordon \& James, 2017) found that brand superiority did not have a direct effect on brand resonance which comprises brand loyalty and more advanced behavioural intentions such as the sense of community and active engagement in sports teams. In terms of professional sports teams, however, the effect of consumers' brand superiority judgments on media consumption behaviours lacks empirical evidence. In addition, it is significant to examine whether the judgment of brand superiority affects media behaviours in this period when matches are played without spectators in the stadium and consumption through the media becomes primarily important. Therefore, based on the results of previous studies, believing that the judgment of brand superiority alone will not have a significant effect on the media consumption behaviours of consumers even during the pandemic, we formed the first hypothesis of the study as follows:

H1: The brand superiority judgments of sport team consumers about their team do not have a direct impact on media consumption behaviours.

On the other hand, it is likely that building customer-based brand equity and increasing the market performance of a product through utilising the attractiveness of its brand will continue its importance in sport by growing in the pandemic. Brand equity, defined as "a set of brand assets and liabilities linked to a brand, its name and symbol that add to or subtract from the value provided by a product or service to a firm and/or to that firm's customers" (Aaker, 1991, p. 15) reduce consumers' perceived risk, send a signal of quality (Erdem \& Swait, 1988), and strengthens the social identity of consumers (Underwood et al., 2001). Thus, brand equity which generally consists of brand awareness, brand associations, brand loyalty, perceived quality and other brand assets such as patents and trademarks (Aaker, 1991), influences consumers' future consumption by differentiating a product from the competitors' products (Keller, 1993). In return, an organization having strong brand equity enjoys some sustainable competitive advantages such as charging a premium price, increasing market share (Chaudhuri \& Holbrook, 2001), brand extension (Keller, 1993), and resistance to crises (Farquhar, 1989). Therefore, we believe that brand equity has a direct effect on media consumption behaviours of sport team consumers and also mediates the relationship between brand superiority and media consumption behaviours in 
the pandemic. As a result, we established other hypotheses as follows:

$\mathrm{H} 2$ : Overall brand equity has a direct effect on the media consumption behaviours of sports team consumers.

H3: Overall brand equity mediates the relationship between brand superiority and media consumption behaviours in sports teams.

The results of the study will help sports team managers better understand their consumers and focus on effective resources for designing efficient marketing strategies during the pandemic.

\section{METHODS}

Study design and Sample. The participants of this quantitative study were 232 volunteer football consumers who support a team in the Turkish Super Football League in Turkey. The data was collected in 3 weeks using the online convenience sampling method, during the ghost games played in stadiums. The sample size recommended for CFA and SEM is 100 to 200 questionnaires (Hair et al., 2006), therefore the sample size is deemed acceptable for analyses. The participants' average age was $\mathrm{M}=35.48 \mathrm{SD}=8.71$ and $78.0 \%$ of whom were men (181) and $22 \%$ were women (51). The participants may not be completely representatives of all football consumers, however showed similar characteristics in terms of gender distribution and age compared with previous research (e.g., $\mathrm{Na}$ et al., 2019; Kunkel et al., 2017), and the average age of the participants was in the range of the primary target group of sport marketers (Bauer et al., 2008), thus the sample seems to fit the purpose of the study.

Research Instruments. In the online questionnaire, the brand superiority scale (6 items) was adapted from Gordon and James (2017). Overall brand equity scale (4 items) was adapted from Yoo and Donthu (2001), who developed a valid and parsimonious multi-dimensional customer-based brand equity scale drawn from Aaker's (1991) and Keller's (1993) conceptualization of brand equity. The media behaviour consumption scale (3tems), which measures the consumption on "TV", "internet" and "printed media" was adapted from Pritchard and Funk (2006). The items were measured using a 5-point Likert scale $(1=$ strongly disagree; $5=$ strongly agree).

Ethical considerations. Participants were presented with an informed consent form according to previously established guidelines (Thomas, Nelson, \& Silverman, 2011). All the participants ticked the consent option on the written informed consent form, which included voluntary participation, the purpose of the study and maintaining confidentiality, the option not to answer any questionnaire items found offensive, or the opportunity to withdraw from the study at any time without justification or penalty (e.g., Rintaugu, Thangu, Oyeyemi, \& Monyeki, 2020).

Statistical analysis. In data analyses, first, confirmatory factor analyses (CFA) were performed for testing structural validity of the multi-item scales. Afterwards, structural equation modelling (SEM) conducted to test the proposed relationships stated in the study. In addition, bootstrapping, one of the most popular and offered mediation testing methods, was used by following Zhao, Lynch, and Chen (2010) in testing direct and indirect paths. The descriptive statistics were performed with SPSS 24, whereas CFA and SEM were performed with the AMOS 26 statistical program.

\section{RESULTS}

Reliability and validity. The CFA was performed for the assessment of the psychometric properties of the measurement models. Since the multivariate normality violated (Mardia's multivariate kurtosis: 52.460 critical ratio: 20.231 ), the parameters obtained from CFA and SEM were evaluated compared to the 5000 re-sampling for the $95 \%$ corrected confidence interval in the bootstrapping method as suggested by Byrne (2001). The results of CFA suggested that the model fits the data well: $\chi 2 / \mathrm{df}=2.171\left(\chi^{2}=134.583 ; \mathrm{df}=\right.$ $.62)$; $\mathrm{SRMR}=.058 ; \mathrm{GFI}=.921 ; \mathrm{CFI}=.960 ; \mathrm{RMSEA}$ $=.071$. The Cronbach's alphas of brand superiority and overall brand equity exceeded the value of .70, however, the Cronbach's alpha of media behaviour (.65) falls slightly below the value of .70, but higher than the acceptable benchmark of $>.60$ according to Hair, Black, Babin, and Anderson (2009). The CFA results and Cronbach's alphas values were given in Table 1.

For the convergent validity, factor loadings were assessed along with average variance extracted (AVE) and composite reliability (CR) estimates. All individual item loadings were above $\geq .50$ (Hair et al., 2006) and significant $(\mathrm{p}<.001)$. For CR, all factors had the suggested benchmark of $\geq .60$ (Fornell \& Larcker, 1981; Bagozzi \& Yi, 1988). In addition, with respect to AVE, all factors had the suggested benchmark of $\geq .50$ (Fornell \& Larcker, 1981) except the media behaviour factor 
Table 1. Confirmatory factor analysis results

Note: ${ }^{a}$-Factor loadings were fixed to the value of $1.0 ; M L$ - maximum likelihood estimation; $\boldsymbol{\beta}$ - original sample estimates of standardized regression weights; ${ }^{*}-\mathrm{P}<.001 ; \boldsymbol{\beta}^{\text {mean }}$ - bootstrapped estimates of standardized regression weights; $S E$ - standard error of bootstrapped estimates; $B C P M$ - Bias corrected percentile method; $C I-$ confidence intervals.

\begin{tabular}{|c|c|c|c|c|c|}
\hline \multirow{2}{*}{ Factors / Items } & \multirow{2}{*}{$\begin{array}{c}\alpha \\
\geq .60 \\
\end{array}$} & \multirow{2}{*}{\begin{tabular}{|c|} 
ML \\
$\boldsymbol{\beta} \geq .50$ \\
\end{tabular}} & \multicolumn{3}{|c|}{$\begin{array}{l}\text { Bootstrapping Estimation } \\
\text { (with } 500 \text { resampling) }\end{array}$} \\
\hline & & & $\boldsymbol{\beta}^{\text {mean }} \geq .50$ & S. E & $\begin{array}{l}\mathrm{BCPM} \\
95 \% \mathrm{CI}_{\text {low }} \mathrm{CI}_{\text {high }}\end{array}$ \\
\hline Brand superiority & .91 & & & & \\
\hline$S U P 1^{a}$ & & .654 & .654 & .051 & $.541 / .743$ \\
\hline SUP2 & & $.859 *$ & .860 & .028 & $.791 / .905$ \\
\hline SUP3 & & $.845^{*}$ & .846 & .025 & $.789 / .889$ \\
\hline SUP4 & & $.656^{*}$ & .654 & .051 & $.548 / .749$ \\
\hline SUP5 & & $.901 *$ & .901 & .018 & $.862 / .933$ \\
\hline SUP6 & & $.845^{*}$ & .845 & .025 & $.786 / .888$ \\
\hline Brand equity & .92 & & & & \\
\hline$E Q T 1^{a}$ & & .836 & .833 & .038 & $.748 / .895$ \\
\hline EQT2 & & $.911 *$ & .909 & .023 & $.852 / .944$ \\
\hline EQT3 & & $.871^{*}$ & .872 & .037 & $.780 / .930$ \\
\hline EQT4 & & $.823^{*}$ & .825 & .042 & $.725 / .894$ \\
\hline Media behaviours & .65 & & & & \\
\hline $\operatorname{Med} 1^{a}$ & & .651 & .655 & .104 & $.486 / .820$ \\
\hline $\mathrm{Med} 2$ & & $.557^{*}$ & .552 & .084 & $.378 / .704$ \\
\hline Med3 & & $.655^{*}$ & .658 & .079 & $.479 / 795$ \\
\hline
\end{tabular}

Table 2. Means, standard deviations, correlations, average variance extracted and composite reliability scores

Note: $A V E$ - average variance extracted; $C R-$ composite reliability; correlation values are the mean correlation values obtained from 5000 bootstrapped re-sampling result. The values in parentheses are squared correlations.

\begin{tabular}{|l|c|c|c|c|c|c|}
\hline \multicolumn{1}{|c|}{ Factors } & Mean & S.D. & $\mathbf{1}$ & $\mathbf{2}$ & $\begin{array}{c}\text { AVE } \\
\geq .50\end{array}$ & $\begin{array}{c}\text { CR } \\
\geq .60\end{array}$ \\
\hline $\begin{array}{l}\text { Brand } \\
\text { Superiority }\end{array}$ & 3.00 & 1,06 & $\mathbf{1 . 0 0}$ & & .64 & .91 \\
\hline Brand equity & 3.01 & 1.10 & $.463(.214)$ & $\mathbf{1 . 0 0}$ & .74 & .92 \\
\hline $\begin{array}{l}\text { Media } \\
\text { behaviours }\end{array}$ & 3.42 & 1.03 & $.283(.080)$ & $.386(.149)$ & .39 & .65 \\
\hline
\end{tabular}

(.39). However, according to Fornell and Larcker (1981), AVE is a more conservative measurement for the validity of the models, and if AVE is below .50 , but CR is above .60 , the convergent validity of the factor is adequate. Since the CR of the factors is above the benchmark level, and all squared correlations between the factors were lower than the AVE of the factors, the internal reliability of the measurement items and discriminant validity was supported (Fornell \& Larcker, 1981). In Table 2 , descriptive statistics, correlations between the factors, the AVE scores and CR were given.

Structural Equation Modelling. The proposed structural model achieved a satisfactory fit to data: $\chi 2 / \mathrm{df}=2.171\left(\chi^{2}=134.583 ; \mathrm{df}=62\right) ; \mathrm{SRMR}=.058$; $\mathrm{GFI}=.921 ; \mathrm{CFI}=.960 ; \mathrm{RMSEA}=.071$. Figure 1

Figure 1. Proposed structural model

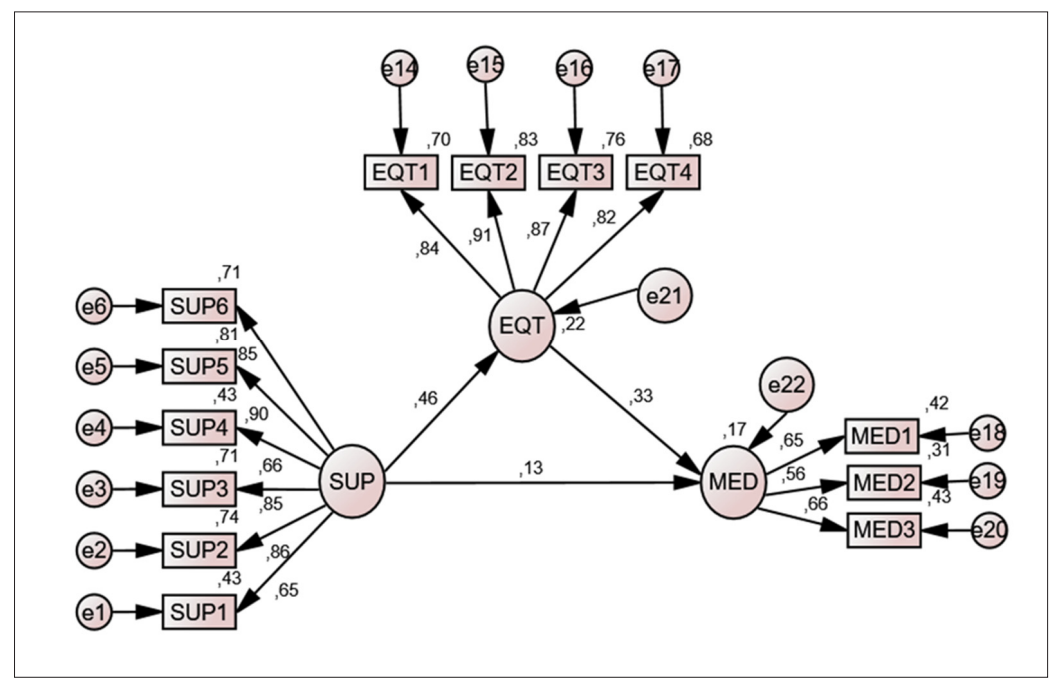


Table 3. Structural equation modelling results

\begin{tabular}{|c|c|c|c|c|c|}
\hline \multirow{2}{*}{ Hypotheses } & \multirow{2}{*}{$\begin{array}{c}\text { ML } \\
\beta\end{array}$} & \multicolumn{4}{|c|}{ Bootstrapping Estimation (with 5000 re-sampling) } \\
\hline & & $\beta^{\text {mean }}$ & SE & BCPM 95\% CI ${ }_{\text {low }} / \mathrm{CI}_{\text {high }}$ & Result \\
\hline \multicolumn{6}{|c|}{ Direct Relationships } \\
\hline $\mathrm{H} 1=$ Brand superiority - media behaviours & .134 & .135 & .113 & $-.098 / .350$ & NS \\
\hline $\mathrm{H} 2=$ Brand equity - media behaviours & $.330 * * *$ & .322 & .099 & $.137 / .520$ & $\mathrm{~S}$ \\
\hline \multicolumn{6}{|c|}{ Indirect Relationships } \\
\hline $\mathrm{H} 3=$ Brand superiority - brand equity - media behaviours & $.154 * * *$ & & .049 & $.069 / .268$ & $\mathrm{~S}$ \\
\hline
\end{tabular}

Note: $M L$ - Maximum likelihood estimation; $\boldsymbol{\beta}$ - original sample estimates of standardized regression weights; $* * *-\mathrm{P}<.001 ; \boldsymbol{\beta}^{\text {mean }}-$ bootstrapped estimates of standardized regression weights; $S E$ - standard error of bootstrapped estimates; $B C P M-$ Bias corrected percentile method; $C I$ - confidence intervals; $S$ - supported; $N S$ - not supported.

shows the results of the proposed relationships in this study. The direct regression coefficient from brand superiority to media consumption behaviours $\left(\mathrm{H} 1: \beta^{\text {mean }}=.134 ; \mathrm{p}>.05\right)$ was not significant, but direct regression coefficient from overall brand equity to media consumption behaviours ( $\mathrm{H} 2$ : $\beta=.330 ; p<.001)$ was significant and positive. In addition, indirect regression coefficient from brand superiority to media behaviours $(\mathrm{H} 3 ; \beta=$ $.154 ; \mathrm{p}<.001)$ was significant and positive. The model also accounted for $22 \%$ of brand equity and $17 \%$ of media behaviours. All the results related to the SEM were presented in Table 3. According to Preacher and Hayes (2008), full mediation can be shown if a non-significant direct path from the independent variable to the dependent variable exists simultaneously with a significant indirect path. In respect to mediation relationships (H3), brand superiority had no significant direct effect on media behaviours; however, it had a significant indirect effect on media behaviours via brand equity. Thus, overall brand equity fully mediated the relationship between brand superiority and media behaviours.

\section{DISCUSSION}

This study aimed to investigate whether brand superiority has an effect on media consumption behaviours, and whether overall brand equity mediates the relationship between brand superiority and media consumption behaviours in spectator sports during the COVID-19 pandemic. It was essential to investigate the influence of brand function, which has an impact on consumers attitude and behaviours, on media consumption behaviours of sport team consumers that became primarily important with the recent lockdown. Results of the study demonstrated that the effect of brand superiority did not have a direct effect on media consumption behaviours of sport team consumers during the pandemic, which confirmed our first hypothesis and the study of Gordon and James (2017), who found similar results before the pandemic conditions. The effect of brand superiority on overall brand equity specifically was not a hypothesis in this study, however, the results have shown the positive and significant effect of brand superiority on overall brand equity $(\beta=.465 ; \mathrm{p}<.001)$, which confirmed Keller's (2001) proposition. The results of the study also have revealed for the first time the significant and positive effect of overall brand equity on media consumption behaviours and the mediation role of overall brand equity on the relationship between brand superiority and media consumption behaviours of sport team consumers. as proposed in the second and third hypothesis respectively. Thus, this study contributed to the sports branding literature by explaining the mechanism of how brand superiority can influence media consumption behaviours and the role of overall brand equity on media consumption behaviours of sport team consumers during pandemic conditions.

\section{CONCLUSIONS}

The evidence in this study that brand superiority did not have a direct effect on media consumption indicates to sport managers that the cognitive judgement of sport consumers, generally related to the more functional aspect of a sports product, alone is not an efficient way to directly influence sport team consumers toward media consumption behaviours, even in the COVID-19 pandemic. Brand superiority, which is generally linked to quality as perceived by consumers, however, is an essential construct to use for establishing overall brand equity. Sports fans differ from consumers of manufactured products concerning their emotional 
attachment (Mastromartino, Qian, Wang, \& Zhang, 2020). Most sports team fans consume the team product (i.e., the game) to fulfil their symbolic (e.g., image congruence) and socio-psychological (e.g., self-enhancement) needs (Yağız, 2020). They also benefit from social connections with others due to team consumption (Mastromartino et al., 2020). Therefore, influencing sport team consumers' behaviours toward media consumptions requires more than just brand superiority in challenging times. Brand equity, however, evidenced in this study to be an effective tool to address for directing sport team consumers' behaviours toward media consumption in the extraordinary circumstance currently exist. It is likely that focusing on more brand awareness, perceived quality, brand loyalty and brand associations, which establish overall brand equity, can increase the market performance of a product especially on media consumption behaviours of sport team consumers. Considering that brand equity is effective in maintaining and expanding the consumer base, parallel to this, broadcasters especially are showing interest in teams having a larger audience, improving brand equity in attracting broadcasters and other commercial partners may be vital, especially for small sports teams to substitute the matchday loss with other revenues.

Since only football team consumers were examined within this study, the generalizability of the result for other sports settings requires consideration. The moderation role of some relationship quality variables towards a sport team such as trust, intimacy and reciprocity between the socio-psychological motivations and media consumption behaviours can be examined in future research. Also, the brand equity and service quality of a broadcaster, and satisfaction with the broadcast that may affect the preferences and purchase intention of the consumers toward a broadcaster, could be considered for furthering this research stream in the context of COVID-19.

\section{Acknowledgements}

\section{Conflicts of Interest}

There is no funding and grant-awarding body and no potential conflict of interest fort his study.

\section{REFERENCES}

Aaker, D. A. (1991), Managing Brand Equity: Capitalizing on the value of a brand name, Free Press, New York, NY.

Bagozzi, R.P. \& Yi, Y. (1988). On the evaluation of structural equation models. Journal of the Academy of Marketing Science, 16(1), 74-94. https://doi. org/10.1007/BF02723327

Bauer, H. H., Sauer, N. E., \& Exler, S. (2005). The loyalty of German soccer fans: does a team's brand image matter? International Journal of Sports Marketing \& Sponsorship, 7(1). https://doi.org/10.1108/IJSMS-0701-2005-B004

Bauer, H. H., Stokburger-Sauer, N. E., \& Exler, S. (2008). Brand image and fan loyalty in Professional team sport: A refined model and empirical assessment. Journal of sport Management, 22(2), 205. https://doi.org/10.1123/ jsm.22.2.205

Byrne, B. M. (2001). Structural Equation Modelling with Amos: Basic Concepts, Applications, and Programming. USA, Lawrence Erlbaum Associates, Publishers.

Chaudhuri, A. \& Holbrook, M. B. (2001). The chain of effects from brand trust and brand affect to brand performance: the role of brand loyalty. Journal of marketing, 65(2), 81-93. https://doi.org/10.1509\%2Fjm kg.65.2.81.18255

Drewes, M., Daumann, F., \& Follert, F. (2021). Exploring the sports economic impact of COVID-19 on professional soccer. Soccer \& Society, 22(1-2), 125-137. https://doi.org/10.1080/14660970.2020.1802256

Deloitte. (2020a). 2019/20 - a season like no other. Retrieved from https:/www2.deloitte.com/fi/fi/pages/ about-deloitte/articles/annual-review-of-footballfinance-2020.html. Accessed 16 March 2021.

Deloitte. (2020b). Annual Review of Football Finance 2020. Sports Business Group June 2020. Retrieved from https:// www2.deloitte.com/content/dam/Deloitte/uk/Documents/ sports-business-group/deloitte-uk-annual-review-offootball-finance-2020.pdf. Accessed 16 March 2021

Deleoitte. (2020c). COVID-19, Football \& Digital: 2020/21 Season \& Beyond. Retrieved from https:// www2.deloitte.com/uk/en/pages/sports-business-group/ articles/covid-19-football-and-digital-2020-21-seasonand-beyond.html. Accessed 16 March 2021.

Erdem, T., \& Swait, J. (1998). Brand equity as a signalling phenomenon. Journal of consumer Psychology. 7(2), 131-157.

Farquhar, P. H. (1989). Managing brand equity. Marketing research, 1(3), 24-33.

Fornell, C., \& Larcker, D. F. (1981). Evaluating structural equation models with unobservable variables and measurement error. Journal of marketing research, 3950. https://doi.org/10.1177\%2F002224378101800104

Gladden, J. M., Irwin, R. L., \& Sutton, W. A. (2001). Managing North American major professional sport 
teams in the new millennium: A focus on building brand equity. Journal of Sport Management, 15(4), 297-317. https://doi.org/10.1123/jsm.15.4.297

Gordon, B. S., \& James, J. D. (2017). The impact of brand equity drivers on consumer-based brand equity in the sport service setting. International Journal of Business Administration, 8(3) pp.55-68. https://doi. org/10.5430/ijba.v8n3p55

Hair, J. F., Black, W. C., Babin, B. J., \& Anderson, R. E. (2006). Multivariate Data Analysis. USA, Pearson Education

Horky, T. (2021). No sports, no spectators-No media, no money? The importance of spectators and broadcasting for professional sports during COVID-19. Soccer \& Society, 22(1-2), 96-102. https://doi.org/10.1080/14660 970.2020 .1790358

Keller, K. L. (1993). Conceptualizing, measuring, and managing customer-based brand equity. The Journal of Marketing, 57(1), 1-22. https://doi.org/10.1177\% 2F002224299305700101

Keller, K. L. (2001). Building customer-based brand equity: a blue print for creating strong brands (pp. 6872). Marketing Science Institute. Working Paper. Report No: 01-107.

Kunkel, T., Funk, D. C. \& Lock, D. (2017). The effect of league brand on the relationship between the team brand and behavioural intentions: A formative approach examining brand associations and brand relationships. Journal of Sport Management, Vol. 31 No. 4, pp. 317-332. https:// doi.org/10.1123/jsm.2016-0166

Marbella International University Centre. 2020. The Impact of the Covid Crisis on the Sport Industry. https:// miuc.org/impact-covid-crisis-sport-industry/. Accessed 16 March 2021.

Mastromartino, B., Qian, T. Y., Wang, J. J., \& Zhang, J. J. (2020). Developing a fanbase in niche sport markets: An examination of NHL fandom and social sustainability in the sunbelt. Sustainability, 12(3), 1115. https://doi. org $/ 10.3390 / \mathrm{su} 12031115$

Na, S., Kunkel, T., \& Doyle, J. (2020). Exploring athlete brand image development on social media: The role of signalling through source credibility. European Sport Management Quarterly, 20(1), 88-108. https://doi.org/1 $0.1080 / 16184742.2019 .1662465$

Preacher KJ. \& Hayes AF. (2008). Asymptotic and resampling strategies for assessing and comparing indirect effects in multiple mediator models, Behavior research methods, 40(3): 879-891. https://doi. org/10.3758/BRM.40.3.879

Pritchard, M. P., \& Funk, D. C. (2006). Symbiosis and substitution in spectator sport. Journal of Sport Management, 20(4), 299-321. https://doi.org/10.1123/ jsm.20.3.299

Rintaugu, E. G., Thangu, E. K., Oyeyemi, A., \& Monyeki, M. A. (2020). Sexual Behavioral Patterns of Kenyan University Student-Athletes: Implications for Sports Managers. Baltic Journal of Sport and Health Sciences, 3(118), 33-42. https://doi.org/10.33607/bjshs. v3i118.962

T. C. Sağlık Bakanlığı, COVID-19 Bilgilendirme Platformu. (2020). Pandemi https://covid19.saglik.gov. tr/TR-66494/pandemi.html. Accessed 16 March 2021.

The Business Research Company. (2020). Spectator Sports Global Market Report 2021: Covid- 19 Impact and Recovery To 2030. https://www. thebusinessresearchcompany.com/report/spectatorsports-global-market-report. Accessed 16 March 2021.

Thomas, J. R., Nelson, J. K., \& Silvermann, A. L. (2011). Research Methods in Physical Activity (6th edition). Canada: Human Kinetics

Underwood, R., Bond, E., \& Baer, R. (2001). Building service brands via social identity: Lessons from the sports marketplace. Journal of Marketing Theory and Practice, 1-13. https://doi.org/10.1080/10696679.2001. 11501881

Yağız, K. (2020). The role of fan identification on the relationship between sports league brand associations and psychological commitment. European Journal of Physical Education and Sport Science, 6(9). https://oapub.org/edu/ index.php/ejep/article/view/3456 Accessed 8 November 2021

Yoo, B., \& Donthu, N. (2001). Developing and validating a multidimensional consumer-based brand equity scale. Journal of business research, 52(1), 1-14. https://doi. org/10.1016/S0148-2963(99)00098-3

Zeithaml, V. A. (1988). Consumer perceptions of price, quality, and value: a means-end model and synthesis of evidence. Journal of marketing, 52(3), 2-22.

Zhao, X., Lynch Jr, J. G., \& Chen, Q. (2010). Reconsidering Baron and Kenny: Myths and truths about mediation analysis. Journal of consumer research, 37(2), pp.197-206. https://doi.org/10.1086/651257 